\title{
Geociências
}

\section{O carste no plano de manejo do Parque Estadual Intervales e zona de amortecimento, Estado de São Paulo, Brasil}

\author{
The karst in the management plan of the Intervales State Park \\ and buffer zone, State of São Paulo, Brazil
}

William Sallun Filho

Doutor, Pesquisador Científico do Instituto Geológico (IG/SMA-SP)

E-mail:wsallun@gmail.com

\section{José Antonio Ferrari}

Doutor, Pesquisador Científico do Instituto Geológico (IG/SMA-SP) E-mail: ferrari.ig2@gmail.com

Silvio Takashi Hiruma

Doutor, Pesquisador Científico do Instituto Geológico (IG/SMA-SP)

E-mail: sthiruma@gmail.com

Alethéa Ernandes Martins Sallun

Doutora, Pesquisadora Científica do Instituto Geológico (IG/SMA-SP)

E-mail: aletheamartins@hotmail.com

Ivo Karmann

Doutor, Professor Doutor, Instituto de Geociências (IGc-USP)

E-mail: ikarmann@usp.br

\section{Resumo}

O Parque Estadual Intervales (PEI) e sua Zona de Amortecimento (ZA), inseridos nos vales dos rios Ribeira de Iguape e Paranapanema, situam-se em domínios de rochas carbonáticas proterozóicas de grande interesse para a mineração, onde se verifica a formação de carste com ocorrência expressiva de cavernas. A caracterização do carste no PEI e ZA para o plano de manejo foi baseada em estudos geológicos e geomorfológicos que permitiram definir o grau de vulnerabilidade à contaminação do aquífero cárstico. As regiões de maior vulnerabilidade do carste no PEI e ZA são aquelas que permitem a introdução direta de contaminantes no aquífero e se caracterizam pela presença de feições cársticas tais como cavernas e sumidouros. Para as regiões onde a recarga ocorre exclusivamente por infiltração difusa e o escoamento superficial converge para rios de superfície, foi associado grau de vulnerabilidade intermediário. Considerando essa análise, foram identificadas áreas com maior potencial para impactos e feitas recomendações para a gestão do parque e sua zona de amortecimento.

Palavras-chave: Carste, vulnerabilidade, plano de manejo, Parque Estadual Intervales, zona de amortecimento.

\begin{abstract}
Located in the valleys of the Ribeira de Iguape and Paranapanema Rivers, where karst features and a large number of caves can be found, the Intervales State Park and its buffer zone lie within an area of Proterozoic carbonate rocks that are of great interest to the mining industry. Based on geomorphological and geological studies, the characterization of the karst was performed in order to develop a management plan for the Intervales State Park and its buffer zone. With this, it was possible to define the degree of vulnerability of the karst aquifer to contamination. The areas of greatest vulnerability are those that facilitate injection of contaminants directly into the aquifer, being characterized by such karst features as caves and sinks. In regions where recharge occurs exclusively via diffuse infiltration, and runoff convergence with surface watercourses, the degree of vulnerability is lower. Considering this analysis, areas with the greatest impact potential were identified and recommendations made regarding management of the park and its buffer zone.
\end{abstract}

Keywords: Karst, vulnerability, management Plan, Intervales State Park, buffer zone. 


\section{Introdução}

O Parque Estadual Intervales (PEI) é uma Unidade de Conservação do Estado de São Paulo criada em 1995 no sentido de promover o desenvolvimento sustentável regional e a conservação da natureza no Vale do Ribeira, frente à necessidade de proteção às áreas de mananciais, aos sítios espeleológicos e às frágeis encostas da serra do $\mathrm{Mar} / \mathrm{Pa}$ ranapiacaba, cobertas pela Mata Atlântica. Esses elementos são reconhecidos constitucionalmente, em níveis federal e estadual, como Patrimônio Nacional.

O PEI localiza-se no Estado de São Paulo, a $270 \mathrm{~km}$ da capital, ocupando uma área de 41.704,27 hectares (Figura 1). Para o Plano de Manejo do parque, foi definida uma Zona de Amortecimento (ZA) correspondente a uma faixa envoltória de 10 km em relação aos limites do PEI. Faz divisa com outras Unidades de Conservação, formando em conjunto com o Parque Estadual Carlos Botelho, o Parque Estadual Turístico do Alto Ribeira (PETAR), a Estação Ecológica de Xitué, a APA da Serra do Mar e a Reserva da Biosfera da Mata Atlântica, o continuum ecológico de Paranapiacaba, um corredor de Mata Atlântica que ultrapassa 120.000 hectares de área.

Está situado na serra de Paranapiacaba, entre os vales dos rios Paranapanema e Ribeira do Iguape, e abrange, parcialmente, os municípios de Ribeirão Grande, Guapiara, Iporanga, Eldorado Paulista e Sete Barras, além de Capão Bonito e Apiaí, na Zona de Amortecimento.

Na área do PEI e da ZA, ocorrem rochas carbonáticas proterozóicas com desenvolvimento do carste, cujas características intrínsecas o tornam susceptível a problemas ambientais. O presente trabalho teve por finalidade caracterizar o sistema cárstico do PEI e da ZA e estabelecer sua vulnerabilidade frente à contaminação do aquífero. Seus resultados decorrem do Plano de Manejo elaborado por Sallun Filho et al.(2008), o qual subsidiou, em conjunto com outros temas, o zoneamento final do PEI e da ZA. O zoneamento, de acordo com o conceito estabelecido pelo Sistema Nacional de Unidades de Conservação (SNUC - Lei N 9.985, de 18 de Julho de 2000), é a "definição de setores ou zonas em uma unidade de conservação com objetivos de manejo e normas específicos, com o propósito de proporcionar os meios e as condições para que todos os objetivos da unidade possam ser alcançados de forma harmônica e eficaz". Como orientação para a sua elaboração, o Roteiro Metodológico de Planejamento (Galante et al., 2002) esclarece que o zoneamento é um "instrumento de ordenamento territorial, usado como recurso para se atingirem melhores resultados no manejo da unidade de conservação". O Zoneamento Ambiental do Plano de Manejo do PEI, que agrega os diversos diagnósticos, foi aprovado no CONSEMA (Conselho Estadual do Meio Ambiente-SP) em 18 de fevereiro de 2009.

\section{Metodologia}

A caracterização do sistema cárstico e de sua vulnerabilidade baseou-se no levantamento de informações geológicas e geomorfológicas, com apoio de técnicas de geoprocessamento. Para elaboração do Plano de Manejo, foi realizado um sobrevôo à área e foram integradas informações decorrentes de projetos anteriores, não tendo sido efetuados levantamentos de campo. Na análise do sistema cárstico, foi considerada não apenas a área de rochas carbonáticas, mas, também, a área de captação alogênica situada em rochas não carbonáticas. Para a avaliação dos fenômenos cársticos utilizaram-se: a) base geológica em escala 1:50.000 (Campanha, 2002); b) dados geoquímicos (Gonzalez et al., 1972); c) mapa das feições cársticas de superfície (Hiruma et al., 2007), elaborado a partir de fotografias aéreas 1:25.000; d) mapas temáticos (hipsométrico, declividade, rugosidade, etc.), gerados a partir de dados de elevação do SRTM (2006); e e) lineamentos extraídos do MDT, de imagens LANDSAT 7 ETM+ e de mosaicos semicontrolados de radar (RADAMBRASIL, 1976).

A vulnerabilidade intrínseca do aquífero cárstico levou em conta apenas as características hidrogeológicas do sistema, que são, por definição, independentes das propriedades específicas dos contaminantes. Para Foster e Hirata (1988), a vulnerabilidade de um aquífero à poluição representa as suas características intrínsecas, que determinam sua sensibilidade em ser afetado por um determinado contaminante. Foster et al. (2002) destaca que a delimitação de áreas de proteção em carste é difícil pois os padrões de fluxo são irregulares e com velocidades mais altas do que as calculadas para outros aquíferos. Esses autores também indicam que o mapea-

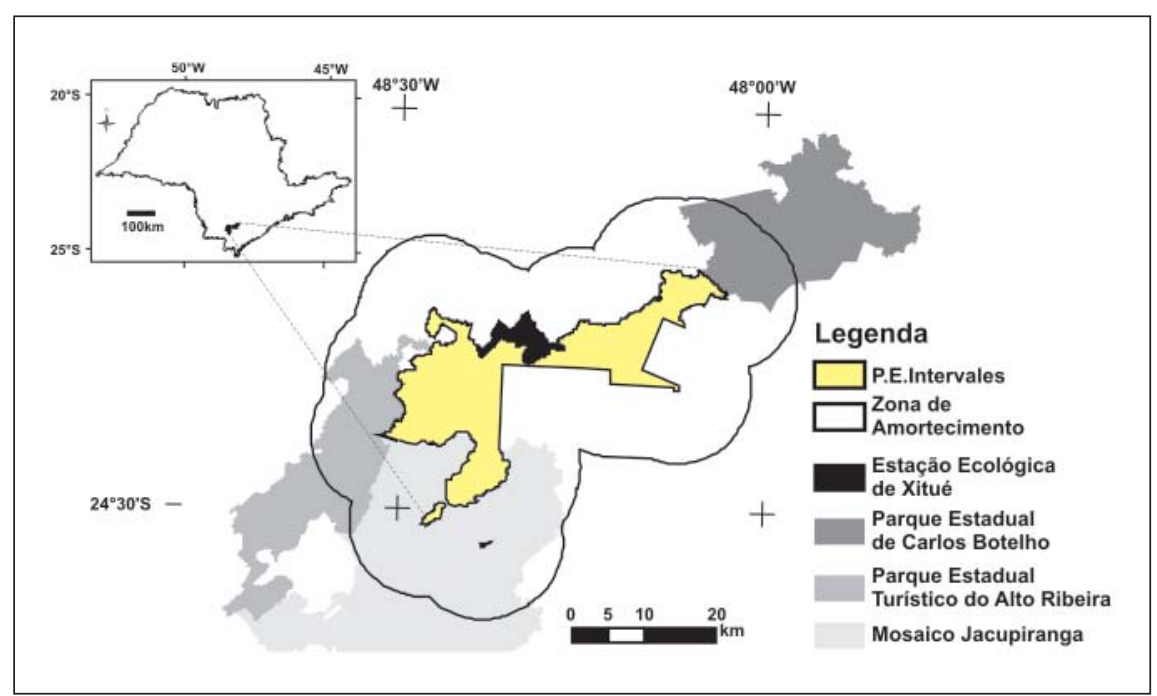

Figura 1 - Localização do Parque Estadual Intervales (PEI), Zona de Amortecimento (ZA) e unidades de conservação adjacentes. 
mento de feições cársticas de superfície e subsuperfície podem auxiliar nessas definições. Uma das abordagens para mapear a vulnerabilidade intrínseca do aquífero cárstico é baseada no modelo origem (risco na superfície) - trajeto (camadas entre a superfície e o topo do aquífero) - alvo (água subterrânea na parte superior do aquífero). Essa abordagem foi amplamente utilizada em mapeamento da vulnerabilidade de aquífero cárstico na Europa (Zwahlen, 2003; Goldscheider, 2005).

De acordo com as premissas apresentadas anteriormente, é possível obter diferentes gradações de vulnerabilidade do aquífero, considerando-se propriedades da cobertura vegetal, a topografia, dos solos, as coberturas sedimentares, as camadas rochosas, a estrutura e a química dos calcários e, até mesmo, a intensidade das chuvas. Levando em conta a complexidade do tema e a falta de controle de alguns dos parâmetros citados, nessa proposta, a vulnerabilidade do aquífero cárstico, na área de estudo, foi determinada a partir das características da infiltração.

Além disso, confrontou-se a vulnerabilidade com a proteção legal, a fim de se estabelecerem as áreas vulneráveis que se encontram fora dos limites das unidades de conservação e que devem merecer maior atenção pelo poder público.

Considerando os limites do PEI e do PETAR e a zona de amortecimento do PEI, foi possível definir áreas que não se encontram protegidas sob o ponto de vista legal, mas que necessitam de proteção, em função de sua vulnerabilidade natural. Essas informações são importantes para balizar discussões futuras sobre a delimitação dessas unidades de conservação e de suas ZAs.

\section{Caracterização do Sistema Cárstico}

Nas regiões sudoeste do Estado de São Paulo e norte do Paraná, ocorrem rochas carbonáticas proterozóicas do Subgrupo Lajeado (Faixa de Dobramentos Ribeira), onde se situam o PEI e sua
ZA. Nessa faixa carbonática, ocorrem os terrenos cársticos e cavernas da "Província Espeleológica do Vale do Ribeira” (Karmann \& Sanchez, 1979), caracterizada por feições cársticas do tipo escarpas rochosas, torres isoladas, dolinas, sumidouros e ressurgências, com cavernas apresentando rios subterrâneos e abismos. Karmann e Ferrari (2002) observam que a região caracteriza-se pela superfície carbonática rebaixada em relação às rochas não carbonáticas, condicionando sistemas cársticos de recarga mista, com predomínio de injeção alóctone. Essa faixa apresenta setores com paisagem cárstica bem desenvolvida, com variadas formas de carste poligonal e trechos fluviocársticos (Karmann, 1994; Karmann \& Sánchez, 1986).

As rochas carbonáticas ocupam 6,5\% da porção W-NW do PEI e ZA, com altitudes entre 137 e 1040 m (Figura 2). O carste insere-se no Cinturão Orogênico do Atlântico de Ross et al. (2008), com áreas mais elevadas (acima de 650 $\mathrm{m})$ ao norte, correspondendo ao Planalto de Guapiara (W-NW do PEI e ZA) e as mais rebaixadas (inferiores a $650 \mathrm{~m}$ ), ao sul, nos morros e escarpas da serra do Mar e Paranapiacaba. O Planalto de Guapiara representa o divisor entre a bacia do Rio Pilões (bacia do Rio Ribeira), com escoamento para sul, e as bacias dos rios das Almas e São José do Guapiara (bacia do Rio Paranapanema), com escoamento para norte (Figura 2). A bacia do Rio Pilões possui gradiente médio de 3,15\% e amplitude de vales variando entre 100 e $800 \mathrm{~m}$, valores esses superiores aos observados nos rios das bacias dos rios das Almas e São José do Guapiara, com gradientes médios de $1,6 \%$ e $1 \%$, respectivamente, e amplitudes de vales entre 115 e 260 m. Além disso, o compartimento dos morros e escarpas da serra do Mar e Paranapiacaba, na bacia do Ribeira, exibe uma maior frequência de declividades acima de 25 graus, ao contrário do observado no planalto de Guapiara, de declividades mais baixas (até 5 graus). O mesmo é observado com relação à rugosidade, que, no planalto de Guapiara, é baixa, entre 1 e 1,011, enquanto que, nos morros e escarpas da serra do Mar e Paranapiacaba, encontrase entre 1,011 e 1,203.

A análise integrada desses índices denota a maior dissecação e entalhamento do relevo no compartimento dos morros e escarpas da serra do Mar e Paranapiacaba. Esse aspecto mostra reflexo direto na forma de desenvolvimento do carste e das cavernas. Ao norte do PEI, na área do Bairro Carioca, inserida na ZA, ocorrem depressões cársticas de baixa amplitude e fundo plano (Figura 3), evidenciando o relevo cárstico menos dissecado na bacia do Rio Paranapanema. Já na bacia do Rio Ribeira (Figura 4), vales, depressões e cones cársticos de grande amplitude denotam a maior dissecação do relevo cárstico.

Na faixa carbonática do PEI e nas porções N-NE e SE da ZA, as rochas carbonáticas apresentam maiores teores de $\mathrm{CaO}$ em relação a $\mathrm{MgO}$ e $\mathrm{SiO}_{2}$, comparativamente às lentes carbonáticas isoladas encontradas a W do PEI. De forma geral, como indicado por Rauch e White (1977), calcários (mesmo aqueles com pequena quantidade de impurezas, ou seja, de sedimentos não carbonáticos) são mais solúveis que os dolomitos. Assim, pode-se concluir que as diferenças observadas na intensidade de carstificação, nos diversos setores, não podem ser atribuídas à composição das rochas carbonáticas.

As bacias que drenam para o carste ocupam área de $206 \mathrm{~km}^{2}$, sendo que 17\% corresponde a bacias autóctones e 83\%, a alóctones (Figura 5). Assim, a contribuição alogênica na recarga do sistema cárstico do PEI, PETAR e ZA é muito significativa. As depressões com contribuição de recarga alóctone seguem o padrão geral do escoamento superficial da região, ou seja, do planalto de Guapiara para os terrenos mais baixos, o que permite a entrada de grandes volumes de água mais acidificada no sistema cárstico, aumentando, ainda mais, a sua evolução como observado na borda oeste do PEI e na porção norte do PETAR. O carste da porção N-NW da ZA, no Planalto de Guapiara, é praticamente 
desprovido de depressões autóctones e bacias alóctones (Figura 5).

Quanto às cavernas, segundo a SBE - Sociedade Brasileira de Espeleologia, em fevereiro de 2006, havia 135 cadastradas no PEI e ZA e no PETAR, sendo que 34 foram re-localizadas por Domingues et al. (2008). O trabalho de Domingues et al. (2008) resultou em 83 cavernas com informações consolidadas, e 59 com dados de desenvolvimento e desnível. O desenvolvimento médio é de 243 m (máximo de 3692 m e mínimo de $5 \mathrm{~m}$ ), sendo que $5 \%$ são maiores que $1000 \mathrm{~m}$ e $63 \%$, menores que $100 \mathrm{~m}$. O desnível médio é de $15 \mathrm{~m}$ (máximo de 174 m e mínimo de 0 m). Destaca-se a gruta dos Paiva (na ZA), que está entre as 50 maiores cavernas do Brasil no levantamento realizado por Auler et al. (2001).

\section{Interferência de processos antrópicos no carste}

As atividades antrópicas podem impactar a paisagem cárstica, acelerando processos morfodinâmicos e/ou contaminando o aquífero. Desse modo, foi possível definir três graus de vulnerabilidade, do maior para o menor, com referência às formas de infiltração: (1) regiões que permitem a introdução direta de contaminantes no aquífero a partir das feições cársticas como sumidouros e cavernas, (2) regiões carbonáticas onde a recarga ocorre, exclusivamente, por infiltração difusa e o escoamento superficial converge para rios de superfície e (3) regiões onde o escoamento não converge para regiões cársticas e não oferecem, portanto, risco para a contaminação do aquífero (Figura 6).

Relacionando o grau de vulnerabilidade natural e as áreas legalmente protegidas, foi estabelecido um zoneamento das áreas cársticas. A ZA não foi considerada como uma unidade de proteção efetiva ao carste (assim como as APA's), visto que diversas atividades são desenvolvidas dentro dela (Figura 7). Na região W-SW da ZA (e fora da

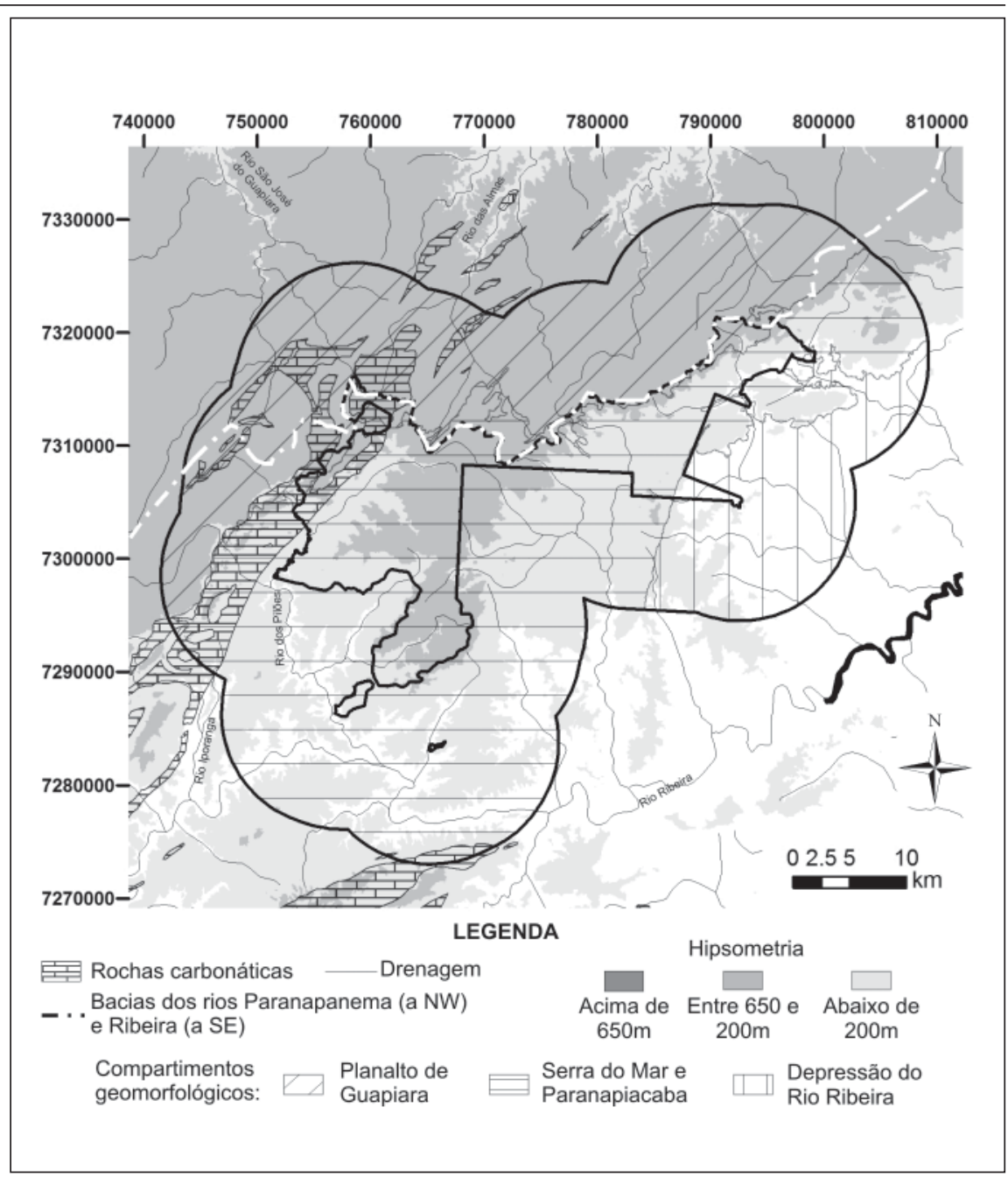

Figura 2 - Distribuição das rochas carbonáticas, mapa hipsométrico simplificado, bacias hidrográficas principais e compartimentos geomorfológicos (Ross et al., 2008) na área do PEI e ZA.

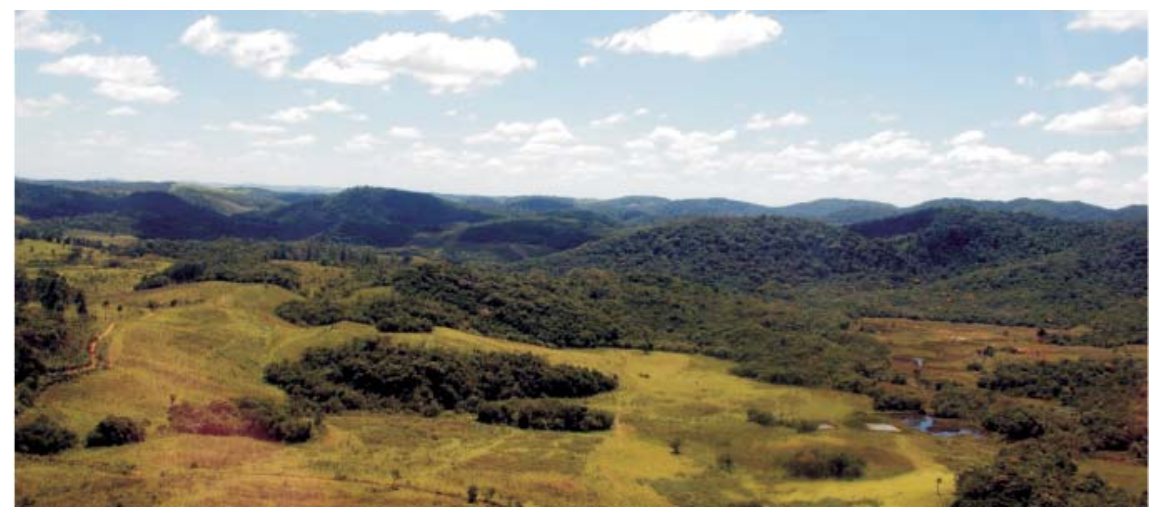

Figura 3 - Grande depressão autóctone de baixa amplitude e fundo plano, na área do Bairro Carioca, bacia do Rio Paranapanema, Zona de Amortecimento do Parque (Ponto 7318387,989N/763531,085 E). 
ZA), as bacias dos rios Temimina e Campina (Figura 8) drenam para o PETAR e podem gerar impactos de poluição. Essas duas bacias são bacias mistas (alogênicas e autogênicas) com grande área de captação alogênica, que drenam para dentro do sistema cárstico, inclusive para sumidouros e cavernas, como as grutas Temimina e Ribeirãozinho, entre outras. Essas duas bacias juntas correspondem a quase $50 \%$ da captação alogênica do carste. A bacia do Córrego Campina está dentro da ZA do PEI, porém totalmente inserida no PETAR, estando, assim, protegida. Entretanto a bacia do Rio Temimina possui parte de suas cabeceiras dentro e fora da ZA do PEI e fora do PETAR, estando, assim, vulnerável, especialmente ao longo da rodovia SP-250 (Guapiara - Apiaí), cujo tráfego de veículos e transporte de cargas diversas são intensos, além de existir maior ocupação humana.

Outras duas áreas foram identificadas como potencialmente susceptíveis por não estarem dentro do PEI e PETAR. São as áreas da gruta dos Paiva (bacia do Córrego do Lajeado) e a área entre o PEI e o PETAR (Figura 8). Atualmente essas áreas não estão em situação de risco a impactos diretos. A primeira, na região da gruta dos Paiva, foi considerada mais vulnerável, pois é uma área de recarga mista, bastante carstificada e que drena para bacias dentro do PEI. Além disso, a gruta dos Paiva representa uma caverna importante, sendo uma das maiores do Estado e está entre as 50 maiores cavernas do Brasil. A segunda área, entre o PEI e o PETAR, mostra-se isolada entre as duas Unidades de Conservação, o que lhe confere relativa proteção. Mesmo assim, encontra-se bastante desmatada com ocupação caracterizada por pequenas propriedades. É uma importante área de captação mista para o carste do PETAR e PEI, com cavernas associadas. Essas áreas foram classificadas como zonas de proteção ao carste no zoneamento final.

A mineração se instalou nessa região há muitos anos e novos empreendimentos vêm surgindo especialmente na área a norte e oeste do PEI (na ZA).

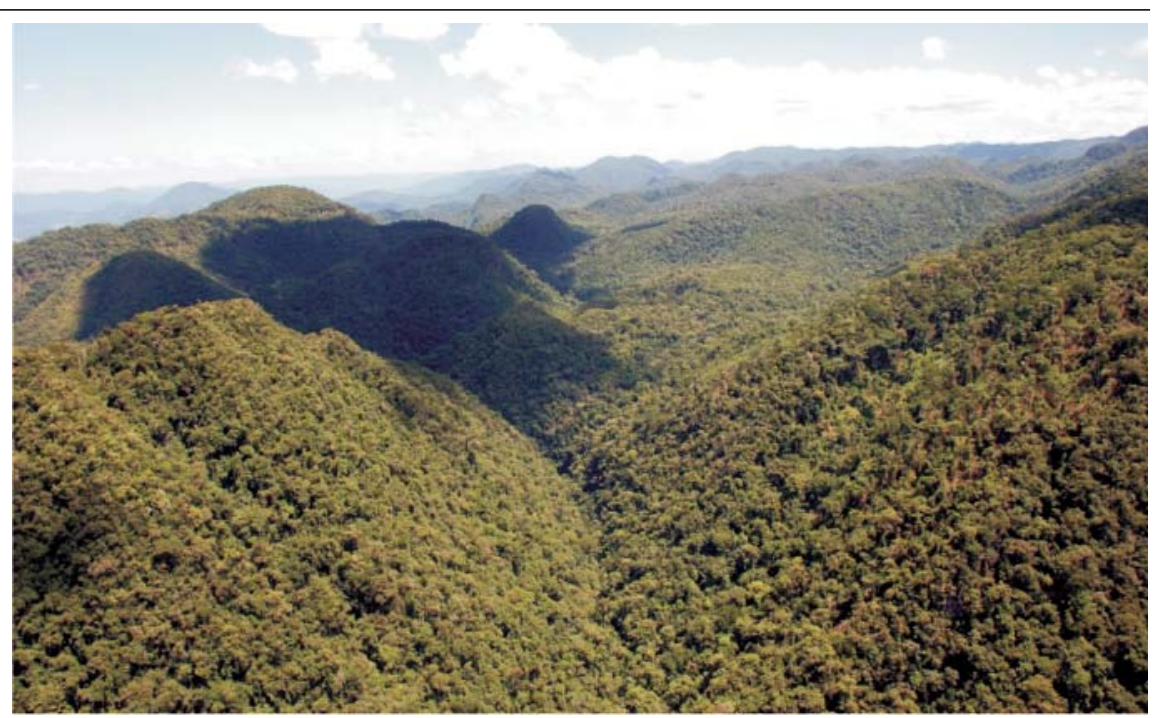

Figura 4 - Vales, depressões e cones cársticos de grande amplitude, na região de Bulhas d'Água (PETAR), bacia do Rio Ribeira (Ponto 7306455,711N/753409,941E).

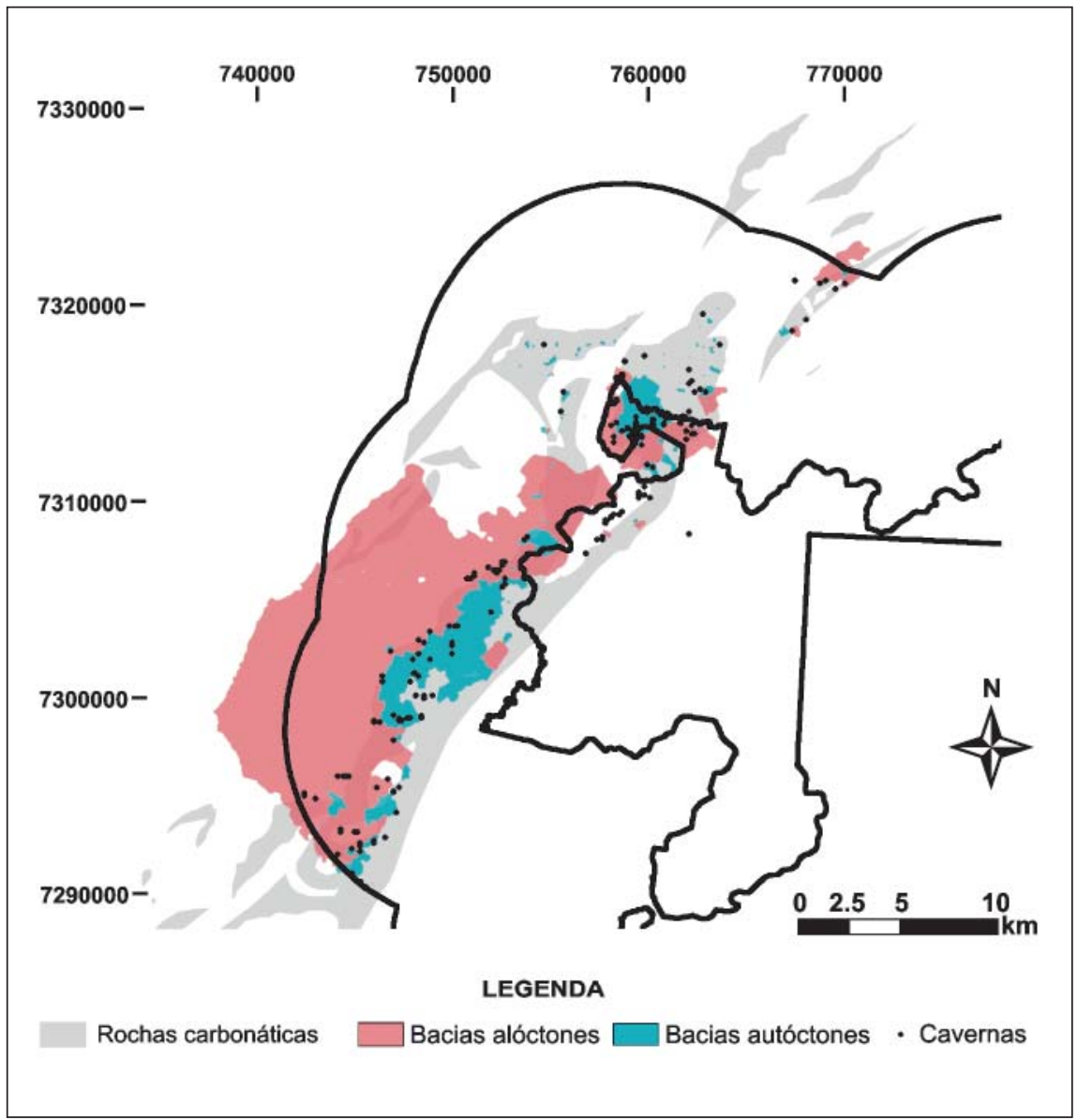

Figura 5 - Distribuição das depressões fechadas no PEI e ZA, segundo Hiruma et al. (2007) e de cavernas segundo SBE - Sociedade Brasileira de Espeleologia (dados de fevereiro de 2006) e Domingues et al. (2008). 


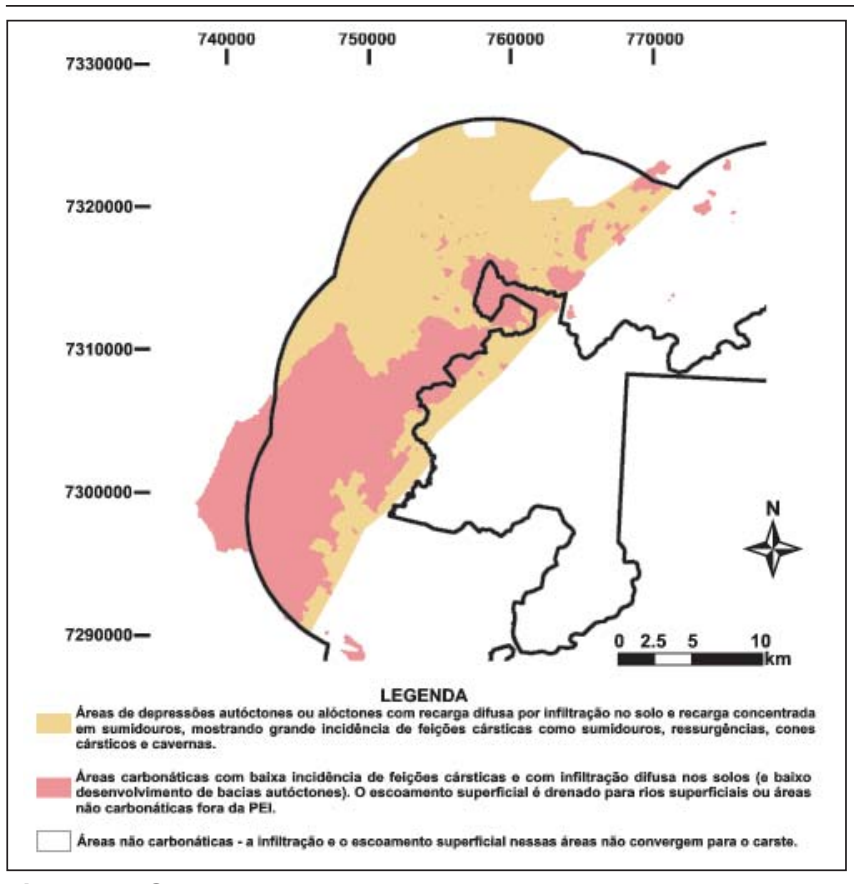

Figura 6 - Graus de vulnerabilidade natural estabelecidos para impactos antrópicos no sistema cárstico do PEI e ZA.

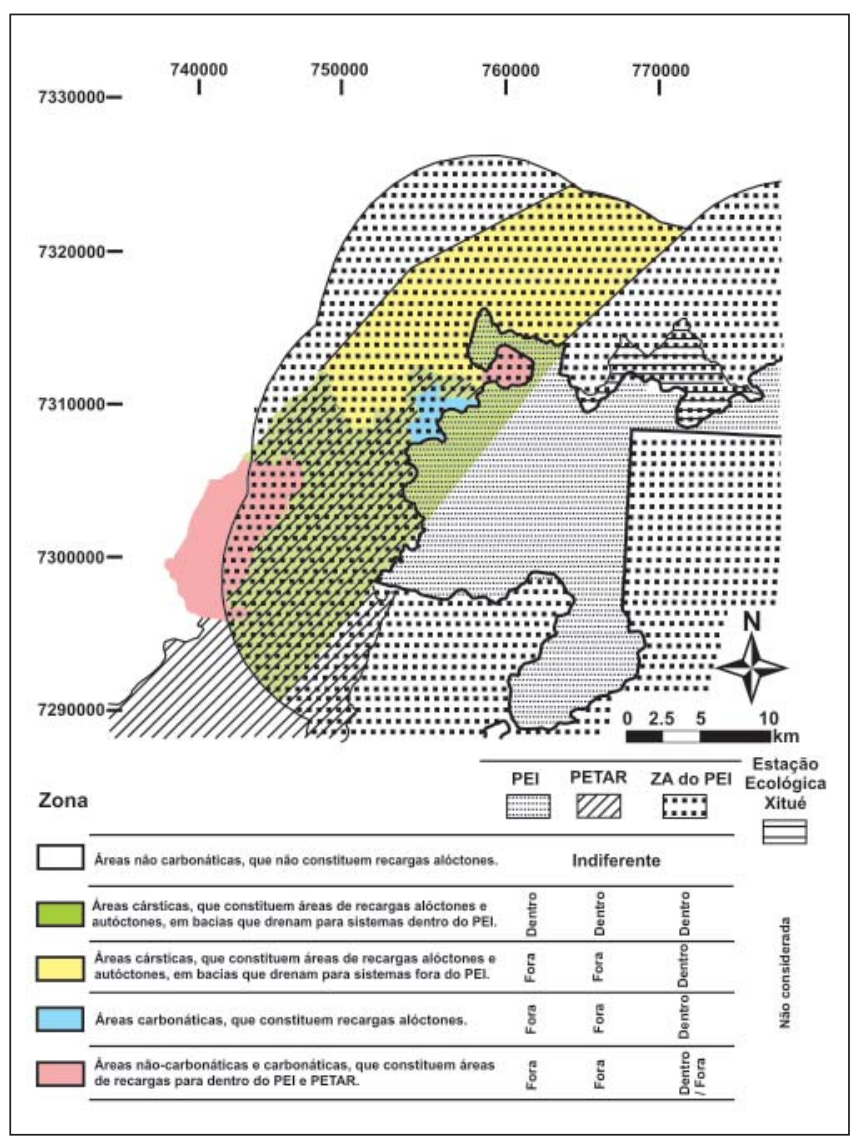

Figura 7 - Zoneamento das áreas cársticas do PEI e ZA com base na vulnerabilidade e áreas legalmente protegidas. As áreas em vermelho e azul são as de maior vulnerabilidade e não estão protegidas do ponto de vista legal, por estarem fora dos limites do PEI e PETAR.
Segundo Shimada et al. (2004), os impactos causados no carste pela mineração são representados por supressão da vegetação, alteração do relevo, alteração de cursos d'água, disposição inadequada de estéril, destruição de cavidades naturais, deslocamento de fauna e alteração do regime hidrológico subterrâneo. Além da mineração, a própria ocupação e outras atividades, como a agricultura, são potencialmente poluidoras. Não ocorrem concentrações urbanas significativas na área, visto que a cidade mais próxima, Ribeirão Grande, está distante e fora do carste. Vilas ocorrem na ZA e devem ter seus esgotos monitorados quando lançados em áreas cársticas. Esse mesmo procedimento deve ser adotado para a própria sede do PEI e toda a infra-estrutura turística lá existente.

Quanto ao turismo, o impacto é pontual, restrito às cavernas e trilhas. Apesar do turismo nas cavernas ser uma forma de aproveitamento econômico sustentável, ele também causa impacto. Boa parte dos visitantes do PEI procura as cavernas como principal atrativo. As medidas de minimização dos impactos são possíveis, tais como visitas monitoradas, que são praticadas no PEI e em alguns locais da ZA. O fluxo de turistas em cerca de 14 (quatorze) cavernas utilizadas no PEI ocorre de forma esporádica, mas, às vezes, de forma intensa. Das cavernas com visitação, duas respondem por 35\% do fluxo de turistas: gruta Colorida e gruta dos Paiva.

\section{Recomendações para o manejo do Sistema Cárstico}

Os dados coletados até o momento são considerados ainda insuficientes para a tomada de decisões quanto à adequada gestão sustentável do Sistema Cárstico do PEI e sua ZA. De forma a atender a legislação vigente e permitir o uso sustentável da região, foram propostas algumas recomendações, apresentadas a seguir.

1) Aumentar a área de abrangência do PEI, englobando as duas áreas do Sistema Cárstico contíguas ao PEI e PETAR, que apresentam importantes feições cársticas e alta restrição ambiental. A primeira área para possível incorporação ao PEI é a área da gruta dos Paiva e a segunda localizase entre o PEI e o PETAR, uma área isolada que não foi abrangida pelas Unidades de Conservação (Figura 8).

2) Elaborar diagnóstico e mapeamento em detalhe das condições atuais do Sistema Cárstico, especialmente no que se refere à localização de feições.

3) Promover o zoneamento de detalhe para se estabelecerem normas de proteção, levando-se em consideração a área de recarga.

4) Estabelecer a política de manejo do Sistema Cárstico e os tipos apropriados de uso, com a determinação de estratégia de proteção de cavidades naturais, do carste e de seu sistema hidrogeológico. 
5) Proporcionar oportunidades educativas e recreativas para visitantes, com o intuito de descobrir, explorar, estudar, respeitar e apreciar as cavidades naturais, definidas pelo respectivo Plano de Manejo Espeleológico, de modo a minimizar os impactos degradantes do uso antrópico.

6) Criar programas em Educação Ambiental.

7) Implantar sistemas para monitorar a degradação do Sistema Cárstico com o uso turístico.

\section{Conclusões}

No carste existe uma interação entre o relevo e a evolução do aquífero. Nessas paisagens, a água subterrânea é um importante agente geomórfico, ocorrendo um feedback positivo: a evolução da drenagem subterrânea influi na evolução do relevo e vice-versa. Assim, a ocorrência de depressões fechadas é indicadora da existência de aquíferos de condutos (aquíferos carstificados). Apesar da ocorrência restrita de rochas carbonáticas no PEI e ZA, esse estudo demonstrou o importante desenvolvimento do carste e de cavernas e, também, relacionou os possíveis impactos. Pode-se inferir a hipótese da maior carstificação no compartimento dos morros e escarpas da serra do Mar e Paranapiacaba, na bacia do Ribeira, do que no planalto de Guapiara, a partir da maior incidência de feições cársticas. As áreas do PEI e PETAR estariam inseridas em áreas de maior carstificação, ao contrário da ZA (excluindo-se o PETAR). As rochas carbonáticas situadas na porção N-NW da ZA, no planalto de Guapiara, são praticamente desprovidas de depressões fechadas autóctones e alóctones, denotando menor carstificação.

Da mesma forma, constatou-se maior freqüência de cavernas na bacia do Ribeira. Nos setores onde as cavernas tendem a ser mais extensas, associa-se um aquífero cárstico mais desenvolvido. Sendo assim, regiões com grande concentração de cavernas são indicadoras de aquíferos bem carstificados. As maiores

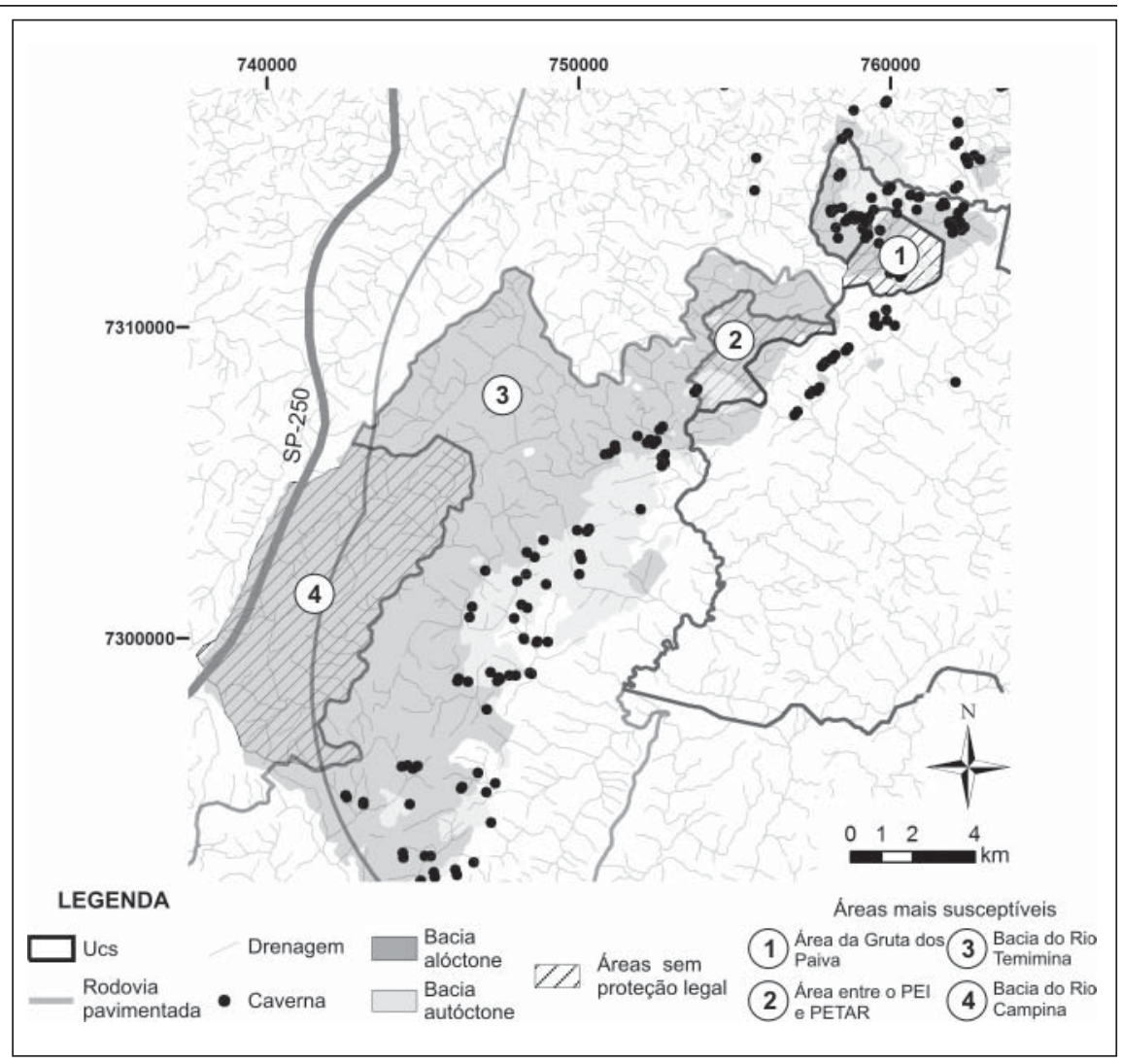

Figura 8 - Detalhe das áreas potencialmente susceptíveis.

cavernas (acima de 500 m de extensão, no total de cinco cavernas) ocorrem na região da transição do planalto para as áreas mais rebaixadas.

Considerando apenas a natureza, extensão e densidade das feições cársticas, determinaram-se como regiões de maior vulnerabilidade do aquífero cárstico no PEI e ZA, aquelas em que há possibilidade de introdução direta de contaminantes. Para as regiões onde a recarga ocorre, exclusivamente, por infiltração difusa e o escoamento superficial converge para rios de superfície, foi relacionado grau de vulnerabilidade intermediário, enquanto que, nas regiões onde o escoamento não converge para regiões cársticas, não se verifica risco para a contaminação do aquífero. Nesse contexto, foram identificadas as seguintes áreas mais susceptíveis a impactos graves de poluição: a bacia do Rio Temimina (W-SW da ZA) e a região da gruta dos Paiva (ZA).

Essa configuração, em conjunto com outros elementos, permitiu o estabelecimento de 5 áreas de proteção do carste no Zoneamento Final para a zona de amortecimento do PEI: três áreas de "proteção do carste e ordenamento territorial” e duas áreas de "interesse à conservação da biodiversidade e proteção integral do carste" (Furlan \& Leite, 2008). O Plano de Manejo do PEI e sua ZA foi, provavelmente, a única unidade de conservação no Brasil a ter realizado estudos específicos em carste, que, a exemplo APA Carste de Lagoa Santa em Minas Gerais (Sousa, 1997), resultou em um zoneamento específico para essas áreas.

\section{Referências bibliográficas}

AULER, A. et al. As grandes cavernas do Brasil. Belo Horizonte: Grupo Bambuí de Pesquisas Espeleológicas, 2001. 228p.

CAMPANHA, G.A. O papel do sistema de zonas de cisalhamento transcorrentes na configuração da porção meridional da Faixa Ribeira. São Paulo: Instituto de Geociências da Universidade de São Paulo, 2002. 105 p. (Tese de Livre Docência). 
DOMINGUES, R. A. P. et al. 3.1.3. Inventário das cavernas do PEI e entorno. São Paulo: Fundação Florestal (FF/SMASP), 2008. 27p. In: FURLAN, S.A., LEITE, S.A. Plano de manejo do Parque Estadual Intervales. Acesso em 05 de janeiro 2010 - Disponível em http://www.fflorestal.sp.gov.br/ media/uploads/planosmanejo/PEIntervales/1.\%20Volume\%20 Principal/cad\%202_DIAGNOSTICO\%20E\%20AVALIACAO/ pag139_164CAVERNAS.pdf.

FOSTER, S. S. D., HIRATA, R. Groundwater pollution risk assessment: a methodology using available data. Lima: Pan American center for sanitary engineering and environmental sciences (CEPIS), 1988. 88 p.

FOSTER, S.S.D. et al. Groundwater Quality Protection - A Guide for Water Utilities, Municipal Authorities and Environment Agencies. TheWorld Bank,Washington, DC, USA, 2002. 103 p.

FURLAN, S.A., LEITE, S.A. 5 Zoneamento. São Paulo: Fundação Florestal (FF/SMA-SP), 2008, 66 p. In: Plano de manejo do Parque Estadual Intervales. Acesso em 05 de janeiro 2010 - Disponível em: Texto: http://www.fflorestal.sp.gov.br/ media/uploads/ planosmanejo/PEIntervales/1.\%20Volume\%20 Principal/cad\%203_BASES\%20LEGAIS_ZONEAMENTO_ PROGRAMAS_BIBLIOGR/pag\%20693_758\%20ZONEAMENTO.pdf; Mapa: http://www.fflorestal.sp.gov.br/media/ uploads/planosmanejo/PEIntervales/1.\%20Volume\%20Principal/cad\%203_BASES\%20LEGAIS_ZONEAMENTO_PROGRAMAS_BIBLIOGR/pag\%20759_760\%20zoneamento\%20 mapa\%20A3.pdf.

GOLDSCHEIDER, N. Karst groundwater vulnerability mapping: application of a new method in the Swabian Alb, Germany. Hydrogeology Journal, v. 13, n. 4, p. 555-564, 2005.

GONZALEZ, L. A. et al. Projeto calcário para cimento. São Paulo: DNPM/CPRM, 1972. v.1 e 2. 151 p.

HIRUMA, S. T. et al. Caracterização morfométrica dos terrenos cársticos das bacias dos Rios Ribeira de Iguape e Paranapanema. In: CARSTE 2007 - Encontro Brasileiro de Estudos do Carste, 2. Resumos expandidos e simples.... São Paulo: Redespeleo Brasil, 2007. v. 1, p. 47-51.

GALANTE, M.L.V. et al. Roteiro metodológico de planejamento - Parque Nacional, Reserva Biológica, Estação Ecológica. Brasília: IBAMA/MMA, 2002. 136 p.

KARMANN, I. Evolução e dinâmica atual do sistema cárstico do alto Vale do Rio Ribeira de Iguape, sudeste do Estado de São Paulo. São Paulo: Instituto de Geociências da Universidade de São Paulo, 1994. 241p. (Tese de Doutorado).
KARMANN, I., SANCHEZ, L.E. Speleological Provinces in Brazil. In: CONGRESO INTERNACIONAL DE ESPELEOLOGIA, 9. Anais.... Barcelona: IUS, 1986, v.1, p. 151-153.

KARMANN, I., SANCHEZ, L. E. Distribuição das rochas carbonáticas e províncias espeleológicas do Brasil. EspeleoTema, v. 13, p. 105-167, 1979.

KARMANN, I., FERRARI, J.A. Carste e cavernas do Parque Estadual Turístico do Alto Ribeira (PETAR), SP. In:

Sítios geológicos e paleontológicos do Brasil. Brasília: DNPM/ CPRM, 2002, v. 1, p. 401-413. 554p.

RAUCH, H. W., WHITE, W. B. Dissolution kinetics of carbonate rocks. 1. Effects of lithology on dissolution rate. Water Resources Research, v. 13, p. 381-394, 1977.

RADAMBRASIL. Folha SG.22-X-B, Mosaico semicontrolado de radar. Escala 1:250.000. Projeto Radambrasil, DNPM, 1976.

ROSS, J. L. S. et al. Geomorfologia. São Paulo: Fundação Florestal (FF/SMA-SP), 2008, 32 p. In: FURLAN, S.A., LEITE, S.A. Plano de manejo do Parque Estadual Intervales. Acesso em 05 de janeiro 2010 - Disponível em http://www.fflorestal.sp.gov.br/ media/uploads/planosmanejo/PEIntervales/1.\%20Volume\%20 Principal/cad\%202_DIAGNOSTICO\%20E\%20AVALIACAO/ pag165_186GEOMORFOLOGIA.pdf.

SALLUN FILHO, W. et al. 3.1.2. Carste. São Paulo: Fundação Florestal (FF/SMA-SP), 2008. 32 p. In: FURLAN, S.A., LEITE, S.A. Plano de manejo do Parque Estadual Intervales. Acesso em 05 de janeiro 2010 - Disponível em http://www.fflorestal.sp.gov. br/media/uploads/planosmanejo/PEIntervales/1.\%20Volume\%20 Principal/cad\%202_DIAGNOSTICO\%20E\%20AVALIACAO/ pag91_138CARSTE.pdf.

SHIMADA, H. et al. Impactos da mineração nas áreas cársticas dos entornos dos Parques Estaduais Petar e de Intervales, SP. In: CARSTE 2004 - Encontro Brasileiro de Estudos do Carste. Resumos.... São Paulo: Redespeleo Brasil, 1, 2004. v. 1. p. 53.

SOUSA, H.A. (coord.) Zoneamento ambiental da APA Carste de Lagoa Santa-MG. Belo Horizonte: IBAMA/CPRM, 1997. 62 p.

SRTM. Shuttle Radar Topographic Mission. NASA: Acesso em outubro de 2006 - Disponível em http://srtm.usgs.gov.

ZWAHLEN, F. Vulnerability and risk mapping for the protection of carbonate (karst) aquifers, final report (COST action 620). European Commission, Directorate-General XII Science, Research and Development, Brussels, 2003. 297 p.

Artigo recebido em 03/09/2009 e aprovado em 19/05/2010.

\section{A REM tem novo endereço: FUNDAÇÃO GORCEIX - REM Rua Carlos Walter Marinho Campos, 57 Bairro: Vila Itacolomy 35400-000 - Ouro Preto - MG}

